\title{
PENGARUH MOTIVASI BELAJAR DAN KECERDASAN NUMERIK SISWA TERHADAP PRESTASI BELAJAR MATEMATIKA
}

\author{
Tuty Kurniawaty Saragih \\ Program Studi Informatika, Universitas Indraprasta PGRI \\ beningsaragih1@gmail.com
}

\begin{abstract}
Abstrak
Penelitian ini merupakan penelitian eksperimen yang menggunakan metode survey. Tujuan dari penelitian ini adalah untuk mengetahui pengaruh motivasi belajar dan kecerdasan numerik siswa terhadap prestasi belajar matematika. Metode penelitian yang digunakan adalah metode survey dengan menggunakan teknik Analisis Korelasional. Hasil penelitian menjelaskan bahwa motivasi belajar memberikan pengaruh positif terhadap prestasi belajar matematika yang ditandai dengan perolehan koefesien determinasi $(\mathrm{R})^{2}$ sebesar $=0,483$ mempunyai makna bahwa 48,3\% Prestasi Belajar Matematika dapat dijelaskan oleh variabel motivasi belajar. Kecerdasan numerik memberikan pengaruh positif terhadap prestasi belajar matematika yang ditandai dengan perolehan koefisien determinasi $(\mathrm{R})^{2}$ sebesar 0,616 mempunyai makna bahwa $61,6 \%$ prestasi belajar matematika dapat dijelaskan oleh variable Kecerdasan numerik siswa. Motivasi belajar dan kecerdasan numerik secara bersama-sama memberikan pengaruh positif terhadap prestasi belajar matematika siswa yang ditandai dengan koefisien determinasi $(\mathrm{R})^{2}$ sebesar 0,824 mempunyai makna $82,4 \%$ Prestasi belajar martematika dapat dijelaskan oleh variable motivasi belajar dan kecerdasan numerik secara bersama-sama.
\end{abstract}

Kata kunci : motivasi belajar, kecerdasan numerik, prestasi belajar matematika

\begin{abstract}
This research was experiment used survey method using Korelasional analysis techniques. Results of the study explained that the motivation of learning provide positive influence toward learning math achievements marked by the acquisition of koefesien determination $\mathrm{R}^{2}=0.483$ of significance that $48.3 \%$ of achievement can learn math variable explained by the motivation to learn. Numerical intelligence provide positive influence toward learning math achievements marked by the acquisition of the coefficient determination $\mathrm{R}^{2}$ of 0.616 has significance that $61.6 \%$ achievement learning math can be explained by the variable numeric Intelligence students. Learning motivation and numerical intelligence together gave a positive influence towards the achievements of the students learn math which is characterized by the coefficient of determination (R) 2 of $0.82482 .4 \%$ meaning the accomplishment of learning math can described by the learning motivation variables and numerical intelligence together.

Keywords : learning motivation, numerical intelligence, mathematics learning achievement
\end{abstract}

\section{PENDAHULUAN}

Untuk menghadapi persoalan siswa maka tugas guru matematika menjadi ganda. Pertama, bagaimana materi ajar sampai kepada siswa sesuai dengan standar kurikulum. Kedua, bagaimana proses pembelajaran berlangsung dengan pelibatan siswa secara penuh, dalam artian proses pembelajaran yang berlangsung dapat berjalan dengan menyenangkan. Sebuah tantangan bagi guru matematika untuk senantiasa berpikir dan bertindak kreatif. Tantangan terbesar adalah bagaimana guru memberikan motivasi kepada siswa agar semangat dalam mengikuti pelajaran matematika sehingga dapat terlihat kecerdasan numerik pada siswa dan dapat menghasilkan prestasi belajar yang baik.

Motivasi merupakan kondisi yang menggerakkan seseorang agar mampu mencapai tujuan dari motifnya [1]. Untuk lebih mendalam tentang motivasi maka terdapat pendekatan-pendekatan terhadap motivasi yang dikelompokkan dalam tiga pendekatan, yaitu : (1) Pendekatan tradisional. Yang disebut dengan pendekatan klasik yang memandang bahwa motivasi para pekerja hanya dipandang dari sudut pemenuhan kebutuhan fisik/biologis 
saja. Dalam pendekatan tradisional lebih berfokus pada kinerja guru sebagai pendidikan. (2) Pendekatan hubungan manusia (human relation approach).

Kecerdasan sebagai; (1) kemampuan untuk menyelesaikan masalah yang terjadi dalam kehidupan manusia; (2) kemampuan untuk menghasilkan persoalan-persoalan baru untuk diselesaikan; (3) kemampuan untuk menciptakan sesuatu atau menawarkan jasa yang akan menimbulkan penghargaan dalam budaya seseorang. Selanjutnya Gardner menyatakan bahwa semua orang memiliki berbagai jenis kecerdasan (kecerdasan majemuk atau multiple intelligence) dengan kadar dan kombinasi yang unik untuk masing-masing orang [2].

Kecerdasan numerik merupakan kecerdasan dalam menangkap serta mengolah data dan angka. Orang-orang dengan kecerdasan numerik mampu membaca angka-angka sama jelasnya dengan membaca huruf. Mereka pun mampu berpikir logis dengan angka-angka, jenis kecerdasan numerik ini sangat diperlukan kecerdasan berpikir logis. jenis kecerdasan numerik ini sangat diperlukan sebagai pilar kecerdasan financial.

Intelegensi logis-matematis adalah kemampuan berpikir dalam penalaran atau menghitung, seperti kemampuan menelaah masalah secara logis, ilmiah, dan matematis, intelegensi ini membuat anak memiliki kemapuan mengenali pola-pola suatu kejadian dan susunannya, mereka senang bekerja dengan angka, ingin mengetahui sejauh mana cara kerja suatu benda. Berikut ini kareakteristik individu yang menunjukkan kemampuan dalam intelegensi logis-matematis :

a. Senang bereskperimen, bertanya, menyusun atau merangkai teka-teki

b. Senang dan pandai berhitung dan bermain angka c. Senang mengorganisasikan sesuatu, menyususn skenario

d. Mampu berpikir logis, bak induktif maupun deduktif

e. Senang silogisme

f. Senang berpikir abstraksi dan simbolis

g. Mengoleksi benda-benda dan mencatat koleksinya.

Identifikasi intelegensi/kecerdasan numerik adalah :

1) Suka menanyakan bagaimana sesuatu hal itu bekerja

2) Menghitung secara cepat

3) Menyukai matematika

4) Menyukai permainan matematika dalam komputer

5) Suka menata macam-macam hal secara teratur, kategorisasi, dan heirarkis

6) Berpikir lebih abstrak dan konseptual dari rata-ata kelas

7) Mempunyai kepekaan dengan sebabakibat dalam suatu persoalan.

Preatasi belajar memahami fakta dan konsep, yaitu keberhasilan siswa memperlajari suatu mata pelajaran khususnya dalam aspek pemahaman fakta dan konsep. Ini dicerminkan melalui kemampuan siswa memahami. Prestasi belajar adalah pencapai atau kecakapan yang dinampakkan dalam keahlian atau kumpulan pengetahuan. [3] Prestasi merupakan hasil usaha yang dilakukan dalam menghasilkan perubahan yang dinyatakan dalam bentuk symbol untuk menunjukkan kemampuan pencapai dalam hasil kerja dalam waktu tertentu.

Tujuan dari Penelitian ini dilakukan untuk mendapatkan gambaran spesifik mengenai pengaruh motivasi belajar dan kecerdasan numerik terhadap prestasi belajar matematika siswa.

\section{METODE}

Berdasarkan fokus permasalahan dan tujuan yang hendak dicapai, penelitian ini 
tergolong ke dalam metode survey karena melakukan pengukuran terhadap hal-hal yang nyata seperti mengukur motivasi belajar, kecerdasan numerik dan prestasi belajar matematika. Metode survey ini digunakan bertujuan untuk memahami sesuatu fenomena (pengaruh motivasi belajar dan kecerdasan numerik siswa terhadap prestasi belajar matematika siswa kelas IX SMP Kecamatan Pancoran Mas Depok). Penelitian ini menggunakan teknik analisis korelasional yakni teknik yang dirancang untuk mengetahui seberapa besar pengaruh antara variabel bebas dengan variabel terikat.

Dalam penelitian ini terdapat 2 variabel bebas yaitu, $X_{1}$ : Motivasi belajar siswa kelas IX, $X_{2}$ : Kecerdasan numerik siswa kelas IX, dan satu variabel terikat yaitu : $Y$ : Prestasi belajar matematika siswa kelas IX. Variabel dalam penelitian ini terdiri dari variabel dependen/terikat, prestasi belajar dan variabel independen/bebas meliputi : motivasi belajar dan kecerdasan numerik siswa.

a. Prestasi belajar dalam penelitian ini disebut variabel kriteria.

b. Motivasi belajar dan Kecerdasan numerik siswa disebut variabel bebas yang merupakan variabel atribut.

c. Teknik pengumpulan data prestasi belajar siswa dalam penelitian ini yaitu dengan cara menyebarkan instrumen hasil belajar matematika pada sampel yang telah ditentukan, setelah melalui pembakuan instrumen seperti validitas, rebilitas dan tingkat kesukaran soal. Skor atau nilai prestasi belajar matematika diperoleh dengan menggunakan instrumen prestasi belajar matematika berjumlah 30 soal pilihan ganda dengan ketentuan siswa yang menjawab benar diberi skor 1 dan yang menjawab salah diberi skor 0 .

\section{HASIL DAN PEMBAHASAN}

a) Pengaruh kecerdasan numerik terhadap prestasi belajar matematika Hasil penelitian secara empiris mengenai pengaruh kecerdasan numerik terhadap prestasi belajar matematika yang dilakukan terhadap siswa-siswi kelas IX SMP swasta di Kecamatan Pancoran Mas Depok menunjukkan bahwa : pengaruh kecerdasan numerik terhadap hasil belajar $61,6 \%$ artinya kecerdasan numerik dapat mempengaruhi atau meningkatkan prestasi belajar matematika sedangkan 38,4\% lainnya dipengaruhi oleh variabel lain.

b) Pengaruh motivasi belajar terhadap prestasi belajar matematika

Hasil penelitian secara empiris mengenai hubungan dan pengaruh motivasi belajar terhadap prestasi belajar metematika yang dilakukan terhadap siswa-siswa di kelas IX SMP swasta di Kecamatan Pancoran Mas Depok menujukkan bahwa : Pengaruh motivasi belajar siswa terhadap prestasi belajar matematika $48,3 \%$, artinya motivasi belajar siswa dapat mempengaruhi atau meningkatkan prestasi belajar matematika sedangkan $51,7 \%$ lainnya dipengaruhi oleh variabel lain.

c) Pengaruh kecerdasan numerik dan motivasi belajar siswa secara bersama-sama terhadap prestasi belajar metematika.

Berdasarkan hasil empiris mengenai hubungan dan pengaruh antara kecerdasan numerik dan motivasi belajar siswa secara bersama-sama terhadap siswa-siswi kelas IX SMP swasta di Kecamatan Pancoran Mas Depok 
menunjukkan bahwa : pengaruh kecerdasan numerik dan motivasi belajar siswa secara bersama-sama terhadap prestasi belajar matematika 67,8\%, artinya kecerdasan numerik dan motivasi belajar siswa secara bersama-sama dapat mempengaruhi atau meningkatkan prestasi belajar matematika sedangkan $32,2 \%$ lainnya oleh variabel lain.

\section{d) Pengujian Persyaratan Analisis}

Pengujian persyaratan analisis dalam penelitian ini menggunakan uji normalitas dan uji linearitas. Pengujian persyaratan analisis data untuk menguji kenormalan dan kelinearan dari data penelitian.

Uji Normalitas syarat untuk melakukan analisa parametrik seperti independen sampel $\mathrm{t}$ test, korelasi bivariate, regresi, dan sebagainya, data penelitian harus terdistribusi secara normal. Tes normalitas menggunakan uji Kolmogorov-Smirnov dengan memakai rumusan hipotesis dan kriteria pengujian sebagai berikut;

\section{Rumusan Hipotesis;}

Ho : Data berdistribusi normal

Ha : Data tidak berdistribusi normal

\section{Kriteria Pengujian :}

Jika Sig. > 0,05, maka Ho diterima Jika Sig. < 0,05, maka Ho ditolak

a. Data tabel Test Normality pada kolom Kolmogorov-Smirnov(a) variabel prestasi belajar Matematika (Y)

Tabel 1: Uji Normalitas Variabel Prestasi Belajar Matematika

One-Simple Kolmogorov-Smimnov Test

\begin{tabular}{llc}
\hline & & $\begin{array}{c}\text { Prestasi Belajar } \\
\text { Matematika }\end{array}$ \\
\hline $\mathrm{N}$ & & 62 \\
Normal Parameters a,b & Mean & 59,2419 \\
& Std. Deviation & 12,37884 \\
Most Extreme & Absolute &, 153 \\
& Positive &, 153 \\
Kolmogorov-Smimov Z & Negative &, 089 \\
Asymp. Sig. (2-tailed) & &, 112 \\
\hline \multicolumn{2}{c}{ a.Test distribution is Normal } \\
b.Calculated from data
\end{tabular}

Dari tabel 1 di atas, diperoleh angka Sig. $0,112>0,05$, maka Ho diterima. Berarti data variabel prestasi belajar matematika berdistribusi secara normal. b. Data tabel Test Normality pada kolom Kolmogorov-
Smirnov (a) variabel kecerdasan Numerik. Data tabel Test Normality di atas pada kolom Kolmogorov-Smirnov(a) variabel motivasi belajar $\left(\mathrm{X}_{2}\right)$ 
Tabel 2 : Uji Normalitas Variabel Motivasi Belajar

\begin{tabular}{llc}
\hline & & $\begin{array}{c}\text { Kemandirian } \\
\text { Belajar }\end{array}$ \\
\hline $\mathrm{N}$ & & 118,9032 \\
Normal Parameters a,b & Mean & 15,02753 \\
& Std. &, 060 \\
Deviation & &, 054 \\
Most Extreme & Absolute &, 060 \\
Differences & Positive &, 474 \\
& Negative &, 978 \\
Kolmogorov-Smimov Z & & \\
Asymp. Sig. (2-tailed) & & \\
\hline a.Test distribution is Normal \\
b.Calculated form data.
\end{tabular}

Dari tabel di atas, diperoleh angka Sig. $0,978>0,05$, maka Ho diterima. Berarti data variabel motivasi belajar berdistribusi secara normal.
Uji Linearitas, berdasarkan hasil pengolahan dengan SPSS vesi 17.0 (Anova tabel kolom $\mathrm{F}$ dan koefisien signifikansi pada baris Deviation from Linierity) diperoleh hasil:

Tabel 3: Uji Linearitas Variabel $X_{1}$ dengan $Y$

\begin{tabular}{|c|c|c|c|c|c|c|c|c|c|}
\hline & & & & & $\begin{array}{l}\text { Sum of } \\
\text { Squares }\end{array}$ & $D f$ & $\begin{array}{l}\text { Mean } \\
\text { Square }\end{array}$ & $F$ & Sig. \\
\hline \multirow{5}{*}{$\begin{array}{l}Y \\
X 1\end{array}$} & \multirow[t]{5}{*}{ * } & \multirow{3}{*}{$\begin{array}{l}\text { Between } \\
\text { Groups }\end{array}$} & (Combined) & & 7566.286 & 31 & 244.074 & 3.631 & .000 \\
\hline & & & Linearity & & 5907.660 & 1 & 5907.660 & 87.884 & .000 \\
\hline & & & $\begin{array}{l}\text { Deviation } \\
\text { Linearity }\end{array}$ & from & 1658.626 & 30 & 55.288 & .822 & .702 \\
\hline & & Within Groups & & 2016.633 & 30 & 67.221 & & & \\
\hline & & Total & & 9582.919 & 61 & & & & \\
\hline
\end{tabular}

Dari table 3 di atas, diperoleh $\mathrm{F}_{\text {hitung }}=0,822$ dan $\mathrm{F}$ tabel $\left(\mathrm{dk}_{1}=30\right)$ dan $\mathrm{dk}_{2}=30=1,84$; karena $F_{\text {hitung }}<F_{\text {tabel }}$ atau $(0,822<1,84)$, maka Ho diterima, artinya regresi berpola linier atau karena Sig 0,702 >0,05, maka Ho diterima, artinya regresi berpola linier.

Tabel 4: Uji Linearitas Variabel $X_{2}$ dengan $Y$

\begin{tabular}{|c|c|c|c|c|c|c|c|c|c|}
\hline & & & & & $\begin{array}{l}\text { Sum } \\
\text { Squares }\end{array}$ & $D f$ & $\begin{array}{l}\text { Mean } \\
\text { Square }\end{array}$ & $F$ & Sig. \\
\hline \multirow{5}{*}{$\begin{array}{l}Y \\
X 2\end{array}$} & \multirow[t]{5}{*}{$*$} & \multirow{3}{*}{$\begin{array}{l}\text { Between } \\
\text { Groups }\end{array}$} & (Combined) & & 7518.836 & 40 & 187.971 & 1.912 & .057 \\
\hline & & & Linearity & & 4435.176 & 1 & 4435.176 & 45.124 & .000 \\
\hline & & & $\begin{array}{l}\text { Deviation } \\
\text { Linearity }\end{array}$ & from & 3083.660 & 39 & 79.068 & .804 & .728 \\
\hline & & Within Groups & & 2064.083 & 21 & 98.290 & & & \\
\hline & & Total & & 9582.919 & 61 & & & & \\
\hline
\end{tabular}

Dari table 4 di atas, diperoleh $\mathrm{F}_{\text {hitung }}=0,804$ dan $\mathrm{F}_{\text {tabel }}, \mathrm{dk}_{1}=39(40)$ dan $\mathrm{dk}_{2}=21(27)=$ 1,84 ; karena $\mathrm{F}$ hitung $<\mathrm{F}$ tabel atau $0,804<$ 1,84, maka Ho diterima, artinya regresi berpola linier atau karena Sig 0,728 > 0,05, maka Ho diterima, artinya regresi berpola linier.

\section{SIMPULAN}

Berdasarkan uraian hasil penelitian di atas, maka dapat disimpulkan bahwa : Pengaruh 
motivasi belajar terhadap prestasi belajar matematika dilihat dari nilai $\mathrm{R}$ Square yang merupakan koefisien determinasi $\left(\mathrm{R}^{2}\right)=$ 0,483 menggambarkan bahwa 48,3\% motivasi belajar dapat mempengaruhi atau meningkatkan prestasi belajar matematika, sedangkan 51,7\% lainnya dipengaruhi oleh variabel lain. Persamaan regresi $\hat{Y}=-8,804$ $+0,572 \mathrm{X}$, artinya jika skor motivasi belajar mengalami kenaikan satu poin maka skor prestasi belajar matematika akan mengalami kenaikan sebesar 0,572 pada konstanta $-8,804$, dan pengaruh kecerdasan numerik dan motivasi belajar secara bersama-sama terhadap prestasi belajar matematika dilihat dari nilai $\mathrm{R}$ Square yang merupakan koefisien determinasi $\left(\mathrm{R}^{2}\right)=$ 0,678 menggambarkan bahwa 67,8\% kecerdasan numerik dan motivasi belajar secara bersama-sama dapat mempengaruhi atau meningkatkan prestasi belajar matematika, sedangkan $32,24 \%$ lainnya dipengaruhi oleh variabel lain. Persamaan regresi ganda $\hat{\mathrm{Y}}=-70,250+0,738 \mathrm{X}_{1}+$ 0,269 $\mathrm{X}_{2}$, artinya jika tiap-tiap variabel mengalami kenaikan satu point, maka prestasi belajar matematika akan mengalami kenaikan sebesar 0,738 dari $\mathrm{X}_{1}$ dan 0,269 dari $X_{2}$ pada konstanta -70,250. Kontanta a pada persamaan regresi ganda tidak signifikan atau tidak berarti, sedangkan koefisien regresi $b_{1}$ pada kecerdasan numerik dan b2 pada motivasi belajar siswa bersifat signifikan atau berarti.

Untuk meningkatkan kecerdasan numerik siswa maka seorang pendidik harus berusaha mengenali karakteristik masingmasing anak dan jangan disamaratakan, berusaha mengenali bagaimana emosi setiap siswa, mampu memahami keinginan siswa, dan selalu menunjukkan rasa kasih sayang selaku pendidik dan orang tua, kemudian seorang pengajar sebaiknya mampu dan sabar melayani setiap keingintahuan siswa dan guru tidak monoton memperbincangkan masalah materi atau guru selalu menjadi sumber materi, gunakan atau manfaatkan sarana pembelajaran semaksimal mungkin seperti laboratorium, perpustakaan dan lain-lain;

\section{DAFTAR PUSTAKA}

[1] Syaiful Bahri Djamanah, Strategi Belajar Mengajar, Reneka Cipta, 2010.

[2] Arikunto, Suharsimi. Dasar-dasar Evaluasi Pendidikan (Edisi Revisi). Jakarta: Bumi Aksara. 2009.

[3] Muhibbin Syah, Psikologi Pendidikan dengan Pendekatan Baru, Rineka Cipta. 2003 